\title{
Las Sociedades Cooperativas y Laborales como artífices del emprendimiento empresarial. Análisis comparativo del Perfil del emprendedor de ambas figuras en el contexto de Andalucía
}

\section{Mario Cuadrado Serrán y Antonio Manuel Ciruela Lorenzo}

\section{RESUMEN}

El objetivo de este artículo es analizar las características y problemáticas de las dos figuras de la Economía Social que más desarrollo están teniendo en los últimos años como motores de emprendimiento empresarial en Andalucía. Nos referimos a las sociedades cooperativas y laborales, las cuales, aunque han sido estudiadas desde diversas perspectivas, no encontramos en la literatura económica estudios en profundidad sobre el análisis del emprendedor, al menos en lo que a la comunidad autónoma andaluza se refiere.

De esta forma, y mediante un análisis comparativo, se establecen las posibles ventajas e inconvenientes de ambas figuras empresariales y se presentan, mediante un estudio empírico, las particularidades personales, sociales y económicas de los emprendedores que deciden acogerse a cada una de ellas, tratando de establecer lo que podríamos denominar como el perfil del emprendedor tipo de Economía social en Andalucía.

PALABRAS CLAVE: Economía Social, emprendimiento, Cooperativas, Sociedades Laborales, perfil tipo, Andalucía.

CLAVES ECONLIT: M190, L260, P130, J540, M100.

Cómo citar este artículo: CUADRADO, M. \& CIRUELA, A.M. (2015): "Las Sociedades Cooperativas y Laborales como artífices del emprendimiento empresarial. Análisis comparativo del Perfil del emprendedor de ambas figuras en el contexto de Andalucía", CIRIEC-España, Revista de Economía Pública, Social y Cooperativa, 84, 5-34.

Correspondencia: Mario Cuadrado Serrán, Licenciado en Economía, y Antonio Manuel Ciruela Lorenzo, Doctor en Ciencias Empresariales, Universidad de Málaga. E-mails: mcuadrado@andaluciaemprende.es y acl@uma.es. 


\section{Les sociétés coopératives et professionnelles en tant qu'artisans de l'entrepreneuriat professionnel. Analyse comparative du profil entrepreneurial dans les deux cas, dans le contexte de l'Andalousie}

RÉSUMÉ : L'objectif de cet article est d'analyser les caractéristiques et les problématiques des deux figures de l'économie sociale s'étant le plus fortement développées au cours des dernières années en tant que moteurs de l'entrepreneuriat professionnel en Andalousie. Nous faisons référence aux sociétés coopératives et professionnelles, qui, bien qu'ayant été étudiées depuis diverses perspectives, ne figurent pas dans la littérature des études approfondies sur l'entrepreneur, au moins en ce qui concerne la communauté autonome d'Andalousie.

De cette manière et grâce à une analyse comparative, nous établirons les éventuels avantages et inconvénients des deux figures entrepreneuriales et nous présenterons par le biais d'une étude empirique les particularités personnelles, sociales et économiques des entrepreneurs qui décident de bénéficier de chacune d'elles, en tentant de déterminer ce qui pourrait être considéré comme le profil de l'entrepreneur type de l'économie sociale en Andalousie.

MOTS CLÉ : Économie sociale, entrepreneuriat, coopératives, sociétés professionnelles, profil type, Andalousie.

\section{Cooperative Societies and Labour Companies as architects of entrepreneurship. Comparative analysis of the entrepreneurial profile of both types of company in the context of Andalusia}

ABSTRACT: The aim of this paper is to analyse the characteristics and problems of the two types of social economy company that have shown the greatest growth in recent years -cooperatives and labour companies-as motors of entrepreneurship in Andalusia. Although they have been studied from various perspectives, no in-depth studies analysing entrepreneurs were found in the literature, at least as far as the Andalusian Autonomous Community is concerned.

A comparative analysis was therefore carried out to establish the potential advantages and disadvantages of the two company types and an empirical study was conducted to examine the particular personal, social and economic traits of entrepreneurs who have decided to form a company of one of these types, trying to establish what might be termed the profile of the typical social economy entrepreneur in Andalusia.

KEY WORDS: Social Economy, entrepreneurship, Cooperatives, Labour Companies, profile type, Andalusia. 


\section{1.- El factor humano en las empresas de Economía Social}

En este mundo competitivo y globalizado las empresas persiguen ser cada vez más eficientes buscando permanentemente sistemas productivos más innovadores. Con este fin, recurren a todos los medios disponibles para lograr cumplir con sus objetivos. En este contexto, la óptima administración y gestión del factor humano tiene singular importancia para el éxito de la competitividad empresarial.

Es evidente que el elemento humano es un factor clave en el desarrollo empresarial actual (Ciruela, 2006), y así lo han afirmado diversos estudios como, por ejemplo, el realizado por Peters y Waterman (1984) en el que se establece que las empresas excelentes son aquellas capaces de adaptarse fácilmente a los cambios del entorno, encontrando en las mismas atributos como flexibilidad organizativa, adhocracia, sensibilidad y preocupación por el elemento humano, fomento de la iniciativa y participación del personal, cadena de mando flexible, abundancia de incentivos no económicos y existencia de ideas y valores compartidos. Características que, en mayor o menor medida, vuelven a repetirse en palabras de otros autores más recientes al considerar como factores de éxito empresarial, entre otros, los siguientes (Aranzadi, 1992; Vargas ,1995; Maestro, 1998; Ridderstrale y Kjell, 2004; Buckingham, 2006; Westall, 2007; Birkinshaw, Hamel y Mol, 2008; Sempere y Hervás-Oliver, 2011; Parga, Martín y Criado, 2013): a) personas como lo más importante en la organización; b) actuaciones éticas y consecuentes; $c$ ) beneficio repercutido a los empleados; d) cultura empresarial compartida y fuertemente arraigada; e) estructuras y organigramas horizontales; f) comunicación clara y transparente; g) formación continua; h) trabajo en equipo; i) fomento de creatividad e innovación; j) sentido de pertenencia y compromiso de sus miembros.

Elementos que revelan al componente humano y a la forma de ser conducido hacia su efectiva implicación e integración como uno de los factores más importantes para la consecución de ventajas competitivas sostenibles (Ciruela, 2006). En este mismo sentido se pronuncia el profesor Vargas (1999), argumentando que la ventaja competitiva no está en las máquinas sino en las personas y en sus iniciativas, creatividad e innovación.

Sin lugar a dudas, un elemento fundamental en el factor humano empresarial es la figura del Emprendedor. Para McClelland (1961), Kuriloff y Hemphill (1983) o DEMAC (1991), el emprendedor es una persona que posee ciertas necesidades psicológicas básicas. Más concretamente, McClelland especifica tres tipos de necesidades: necesidad de logro, necesidad de afiliación y necesidad de poder; siendo la necesidad de logro la más importante y dominante para determinar sus actitudes y actuaciones correspondientes. DEMAC, por su parte, señala algunas necesidades más: necesidad de independencia y autonomía, necesidad de dominio de su medio y necesidad de crear. 
Kuriloff y Hemphill (1981) señalan que el emprendedor es una persona que se compromete con la tarea, que afronta el riesgo moderado, que evalúa las oportunidades, que piensa objetivamente, que busca la retroalimentación, que es optimista y proactivo y que tiene una actitud de logro orientada más allá del dinero.

Según Lambing y Kuehl (1997), el emprendedor es una persona que tiene los siguientes atributos: confianza, determinación, tenacidad, tolerancia a la ambigüedad, creatividad, visión y orientación a los detalles (perfeccionismo). Que finalmente usa todos estos recursos (cualidades) para generar "bienestar", según Ronstadt (1985).

Shapero y Sokol (1982), establecen que la acción de emprender es el hecho de "tomar la iniciativa, consolidar los recursos, gestionar la empresa, actuar con autonomía y asumir el riesgo". En esta misma línea, Stevenson, Roberts, Grousbeck (1985), consideran emprender como un continuo de actuación en el que en un extremo se identifica un promotor que considera que puede "hacer pasar las cosas" $y$ en el otro extremo un administrador eficiente de recursos que los combina para aprovechar las oportunidades.

Para Wennekers y Thurik (1999) emprender es poner en marcha un nuevo proyecto empresarial asumiendo el riesgo que éste conlleva, a cambio de obtener un beneficio empresarial. Es un motor de innovación, competitividad y crecimiento. Sin embargo hay un acuerdo generalizado en que emprender involucra la toma de decisiones, y, en particular, implica contar con las "competencias" necesarias para poder tomar dichas decisiones de la manera correcta, y esto abarca diversos aspectos 0 elementos a considerar. Tal y como señalan VanderWerf y Brush (1989), emprender es una actividad de negocios que consiste en una intersección de las siguientes conductas:

- Creación: establecimiento de una nueva unidad de negocio.

- Administración general: dirección apropiada para una buena utilización de recursos.

- Innovación: generación y explotación comercial de nuevos productos, servicios procesos, mercados, sistemas de organización, etc.

- Aceptación del riesgo: la capacidad para manejar el riesgo de fallas potenciales al tomar decisiones o realizar acciones.

- Mejor desempeño: el intento por lograr altos niveles de desempeño o de crecimiento.

John Burch (1986), por su parte, agrega a la lista anterior más rasgos característicos de las personas emprendedoras:

- Trabajadores incansables: trabajo-adictos (workaholics) que se enfocan a sus metas y trabajan incansablemente para alcanzarlas.

- Optimistas: consideran que cualquier cosa es posible y que el momento es inmejorable para alcanzar metas y logros.

- Orientación a la excelencia: su deseo de logro los lleva a hacer las cosas al mejor nivel posible para sentirse aun más orgullosos y satisfechos de lo alcanzado. 


\section{LAS SOCIEDADES COOPERATIVAS Y LABORALES COMO ARTÍFICES DEL EMPRENDIMIENTO EMPRESARIAL. ANÁLISIS COMPARATIVO DEL PERFIL DEL EMPRENDEDOR DE AMBAS FIGURAS EN EL CONTEXTO DE ANDALUCÍA}

Un elemento que no se ha señalado hasta este momento es el "riesgo", el cual algunos autores establecen como una característica fundamental y, por tanto, base de la definición de emprender, ya que consideran al emprendedor como un "tomador de riesgos", que pondera los beneficios y asume los riesgos que implique alcanzarlos (Baty, 1990). Hiam y Olander (1991), definen al emprendedor como un individuo que "inicia, administra y asume los riesgos y recompensas de un nuevo negocio". Halloran (1992) señala que los emprendedores son individuos dispuestos a asumir riesgos y afrontar sus propias ganancias y pérdidas. Para Gray y Cyr (1994), el emprendedor es "alguien que organiza, controla y asume riesgos en un negocio, ante su deseo por enfrentar desafíos, la oportunidad de alcanzar logros y el impulso de cumplir necesidades personales, emocionales y psicológicas". Mientras que Longenecker, Moore y Petty (1994) lo definen como una persona con "aptitud para innovar y disposición para asumir el riesgo". Stacey (1980), agrega otro elemento interesante en el perfil del emprendedor relacionado con la aceptación del riesgo y es la capacidad para aprender de los errores 0 fracasos, y señala que el emprendedor es una persona capaz de caer y levantarse con una nueva perspectiva de las cosas y un aprendizaje que le permitirá mejorar su desempeño.

En este sentido, iniciar un proyecto empresarial constituye un gran reto. Un emprendedor detecta una oportunidad empresarial, la analiza y proyecta su plan de negocio para crear una organización. Poner en marcha un proyecto empresarial conlleva implícitamente una serie de características personales y profesionales. A rasgos generales, una persona emprendedora se caracterizaría por disponer de las siguientes cualidades esenciales: a) creatividad e innovación; b) confianza y claridad de ideas; c) flexibilidad y adaptabilidad al cambio; d) capacidad de asumir riesgos y afrontarlos; e) capacidad para establecer prioridades; f) visión positiva de los problemas; g) sociabilidad y capacidad de comunicación; h) capacidad organizativa y de planificación; i) optimismo; j) visión de futuro y coherencia; k) tenacidad y persistencia; I) competitividad; $m$ ) integridad y responsabilidad; $n$ ) capacidad de aprendizaje y retroalimentación.

En lo que se refiere a la Economía Social, los emprendedores de este sector se distinguen, sin embargo, por el cariz más social que lucrativo en el desarrollo de su actividad, contribuyendo al interés colectivo y la generación de empleo estable; apuestan por la calidad de los procesos productivos, como garantía de su sostenibilidad, vinculando su actividad al territorio donde se localizan, frente a otras concepciones más impersonales, presentando una elevada frecuencia de trabajo colaborativo y asociativo. Este tipo de iniciativas emprendedoras generan un gran impacto socioeconómico contribuyendo a la generación de una economía sostenible para el progreso económico y social, favoreciendo la cohesión social y territorial, representando un movimiento característico singular.

El Manifiesto-Programa del I Congreso de la Economía Social celebrado en Madrid en 1993, organizado por el Comité Español Permanente de la Economía Social, define a la Economía Social como (CEPES, 1992):

"Toda actividad económica, basada en la asociación de personas en entidades de tipo democrático y participativo, con la primacía de las aportaciones personales y de trabajo sobre el capital." 
Por tanto, uno de los aspectos fundamentales por los que se caracterizan, por ejemplo, las sociedades cooperativas y las sociedades laborales no es otro que la primacía otorgada al elemento humano en el desarrollo de su actividad, estableciéndose los objetivos y organización del trabajo en base a las necesidades y circunstancias de sus socios. Con esto queremos decir que muchas de las características de éxito que se acaban de enunciar están presentes en la propia naturaleza, filosofía y principios cooperativos (Ciruela, 2003); éstas empresas consideran al individuo como el centro de sus actividades, otorgándoles autonomía y fomentando una cultura basada en valores como la igualdad, la participación y la comunicación. Circunstancias por las que podemos establecer que teóricamente, y en relación a estos aspectos, parten de una mejor posición para el desarrollo de su actividad y la adaptación a los continuos cambios del entorno (Ciruela, 2006).

Las empresas de Economía Social presentan importantes ventajas con respecto al resto de organizaciones. De manera más concreta y específica, y siguiendo al profesor Ballestero (1993), se pueden enunciar las siguientes:

1) Espíritu del círculo de calidad. Como la empresa se articula en un equipo de pocos trabajadores, normalmente, es relativamente fácil la comunicación entre ellos. Los socios de este pequeño equipo, en contacto permanente unos con otros, se comunican sugerencias para mejorar la calidad de los productos, reducir los costos, aumentar la facturación y, en definitiva, conseguir un alto índice de logro. La experiencia, capacidad y creatividad de cada socio trabajador son consideradas y aprovechadas plenamente.

2) Ahorro de costos administrativos. Estos costos suelen crecer con rapidez cuando la dimensión de una empresa sobrepasa ciertos límites. Si las economías de escala no llegan a compensar el incremento de los costos administrativos, los resultados de explotación se pueden deteriorar seriamente. Así pues, una pequeña empresa social que opere en sectores poco sensibles a las economías de escala (caso frecuente en los servicios, como la sanidad, los talleres de reparación de vehículos, los restaurantes, etc.) se verá libre de una carga pesada de origen dimensional.

3) Proteccionismo compatible con ajustes laborales. Los socios trabajadores suelen tener relaciones de compañerismo fomentadoras de la cooperación, la comunicación y el aprendizaje. Entre todos harán lo posible y sufrirán los sacrificios necesarios para situarse en posición de máxima eficiencia. A menudo, el compañerismo arranca de antiguo, cuando los socios trabajadores eran un grupo de compañeros (quizá con problemas para conservar su empleo en una empresa capitalista) que decidieron un día abrirse camino creando su propia cooperativa 0 sociedad laboral. 


\section{LAS SOCIEDADES COOPERATIVAS Y LABORALES COMO ARTÍFICES DEL EMPRENDIMIENTO EMPRESARIAL. ANÁLISIS COMPARATIVO DEL PERFIL DEL EMPRENDEDOR DE AMBAS FIGURAS EN EL CONTEXTO DE ANDALUCÍA}

4) Flexibilidad para los cambios estratégicos. En las grandes organizaciones, los cambios de estrategia pueden afectar a los intereses y rutinas de distintos grupos, que se resistirán, tal vez, a ellos. Cuando se trata de grandes empresas sociales, la resistencia a través de las asambleas de socios puede ser severa y retardar la toma de decisiones «reformistas», con los perjuicios consiguientes para la eficacia, hasta el punto de que la empresa y sus programas de producción-mercado corran el riesgo de convertirse en obsoletos. Este riesgo existe también en las pequeñas empresas sociales, pero no por falta de flexibilidad, sino por otras causas (pobreza de capital humano, indecisión).

Por todo lo expuesto, podemos afirmar que las empresas de Economía Social (cooperativas, sociedades laborales y otras entidades asimilables), por su flexibilidad, rapidez de respuesta, adaptación y bajo coste de gestión presentan, al menos potencialmente, importantes ventajas competitivas en numerosos sectores y campos de actividad, pero esto no es suficiente, además, han de poner todo su empeño en aprovecharlas y desarrollarlas.

\section{2.- La creación de empresas de Economía Social en España. Especial referencia a la Comunidad Autónoma de Andalucía}

La importancia que representa la Economía Social en la economía regional de España -como modelo empresarial integrado por empresas de carácter privado que actúan en el mercado produciendo bienes y servicios, que se caracterizan porque en la distribución del beneficio y el proceso de toma de decisiones interno predomina el factor humano frente al capital (Barea, 1991; Defourny y Monzón, 1992; Barea y Monzón, 1996)- es una realidad contrastada durante la última década. Así se evidencia en las bases de datos de las series temporales de las principales magnitudes de la economía española, en las cuales puede observarse el peso que tienen las Cooperativas y las Sociedades Laborales, (siendo estas dos formas jurídicas las principales componentes de la Economía Social), y donde estas empresas actúan como agentes capaces de aglutinar la función económica de crear riqueza con eficiencia y la función social de distribuirla con equidad (véase cuadro $n^{0} 1$ ). 


\section{Cuadro 1. Empresas de Economía Social: Cooperativas y Sociedades Laborales.}

Número de empresas en situación de alta en la Seguridad Social. Distribución por tipo de empresa y Comunidades Autónomas a 31/12/2012

\begin{tabular}{|l|rrrrrr|}
\hline & COOP & $\%$ & SOC. LAB. & $\%$ & TOTAL & $\%$ \\
\hline ANDALUCÍA & 4.033 & 18,76 & 2.838 & 23,08 & 6.871 & 20,33 \\
ARAGÓN & 754 & 3,51 & 445 & 3,62 & 1.199 & 3,55 \\
ASTURIAS & 233 & 1,08 & 453 & 3,68 & 686 & 2,03 \\
BALEARES & 208 & 0,97 & 131 & 1,07 & 339 & 1,00 \\
CANARIAS & 276 & 1,28 & 372 & 3,03 & 648 & 1,92 \\
CANTABRIA & 76 & 0,35 & 114 & 0,93 & 190 & 0,56 \\
CASTILLA-LA MANCHA & 1.294 & 6,02 & 1.087 & 8,84 & 2.381 & 7,05 \\
CASTILLA Y LEÓN & 1.266 & 5,89 & 593 & 4,82 & 1.859 & 5,50 \\
CATALUÑA & 4.773 & 22,20 & 1.086 & 8,83 & 5.859 & 17,34 \\
COM. VALENCIANA & 2.582 & 12,01 & 986 & 8,02 & 3.568 & 10,56 \\
EXTREMADURA & 634 & 2,95 & 303 & 2,46 & 937 & 2,77 \\
GALICIA & 919 & 4,27 & 669 & 5,44 & 1.588 & 4,70 \\
MADRID & 1.044 & 4,86 & 1.367 & 11,12 & 2.411 & 7,13 \\
MURCIA & 1.380 & 6,42 & 722 & 5,87 & 2.102 & 6,22 \\
NAVARRA & 337 & 1,57 & 370 & 3,01 & 707 & 2,09 \\
PAÍS VASCO & 1.533 & 7,13 & 709 & 5,77 & 2.242 & 6,63 \\
RIOJA (LA) & 117 & 0,54 & 39 & 0,32 & 156 & 0,46 \\
CEUTA Y MELILLA & 40 & 0,19 & 10 & 0,08 & 50 & 0,15 \\
\hline TOTAL & 21.499 & 100 & 12.294 & 100 & 33.793 & 100 \\
\hline
\end{tabular}

FUENTE: Elaboración propia. Datos: Ministerio de Empleo y Seguridad Social (2012). Fichero de Códigos de Cuentas de Cotización en la Seguridad Social. DG del Trabajo Autónomo, de la Economía Social y de la Responsabilidad Social de las Empresas.

La comunidad autónoma de Andalucía cuenta en 2012 con 4.033 Cooperativas, siendo la segunda comunidad española (sólo por detrás de Cataluña con 4.733) con mayor número de cooperativas, lo que representa un 18,76\% sobre el total de 21.499 cooperativas existentes en España. Con un total de 2.838 Sociedades Laborales, Andalucía es con un $23,08 \%$ la primera comunidad autónoma de España con mayor número, sobre un total 12.294 sociedades laborales existentes en 2012.

Si consideramos ambos tipos de empresa dentro del conjunto de la economía española, la comunidad autónoma de Andalucía representa con 6.871 cooperativas y sociedades laborales, la comunidad española donde hay mayor número, representando el 20,33\% sobre un total de 33.793 empresas existentes en España a 31 de diciembre de 2012 dadas de alta en la Seguridad Social. 


\section{LAS SOCIEDADES COOPERATIVAS Y LABORALES COMO ARTÍFICES DEL EMPRENDIMIENTO EMPRESARIAL. ANÁLISIS COMPARATIVO DEL PERFIL DEL EMPRENDEDOR DE AMBAS FIGURAS EN EL CONTEXTO DE ANDALUCÍA}

La distribución de las empresas de Economía Social más representativas de la economía española a finales de 2012 se puede observar en el gráfico siguiente:

\section{Gráfico 1. Distribución por tipo de sociedad de alta en la Seguridad Social de España a 31/12/2012}

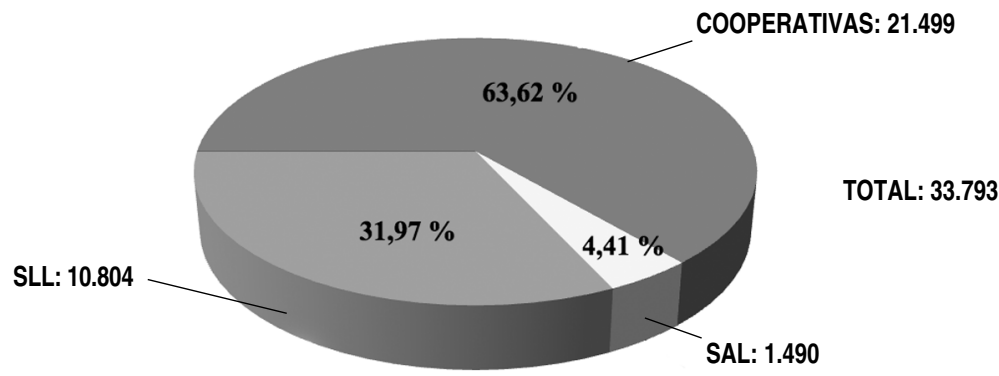

FUENTE: Elaboración propia. Datos: Ministerio de Empleo y Seguridad Social (2012). Fichero de Códigos de Cuentas de Cotización en la Seguridad Social. DG del Trabajo Autónomo, de la Economía Social y de la Responsabilidad Social de las Empresas.

En 2012 hay un total de 33.793 Cooperativas y Sociedades Laborales en España, constituyendo un importante grupo respecto al total de 2.771.967 empresas registradas a 31 de diciembre de 2012 en los ficheros de la Seguridad Social, representando el 1,22\% del total nacional. Estas empresas se distribuyen en 21.499 Cooperativas (63,62\%), 10.804 Sociedades Limitadas Laborales (31,97\%), y 1.490 Sociedades Anónimas Laborales (4,41\%).

La importancia de la Economía Social en España y en Andalucía se refleja en los datos económicos que ofrecen las instituciones económicas y sociales más representativas, como el Ministerio de Empleo y Seguridad Social, la Confederación de Entidades para la Economía Social en Andalucía (CEPES-Andalucía), o la Agencia Estatal de Administración Tributaria (AEAT) en las declaraciones del Impuesto sobre Sociedades.

Si analizamos el empleo registrado por las Cooperativas y Sociedades Laborales, estas empresas ocupan a 354.357 trabajadores, lo que representa el 2,46\% de los 14.407 .064 trabajadores censados en España por el Ministerio de Empleo y Seguridad Social en 2012. Los datos de empleo evidencian el impacto que este tipo de empresas tienen en la economía regional de Andalucía (véase cuadro $\left.n^{0} 2\right)$. 


\section{Cuadro 2. Empleo generado por las Cooperativas y} Sociedades Laborales.

Trabajadores y socios de trabajo en situación de alta en la Seguridad Social.

Distribución por tipo de empresa y Com. Autónomas a 31/12/2012

\begin{tabular}{|l|rrrrrr|}
\hline & COOP & $\%$ & SOC. LAB. & $\%$ & TOTAL $\left(^{*}\right)$ & $\%$ \\
\hline ANDALUCÍA & 53.639 & 18,70 & 13.698 & 20,31 & 67.337 & 19,00 \\
ARAGÓN & 6.412 & 2,23 & 1.726 & 2,56 & 8.138 & 2,30 \\
ASTURIAS & 2.721 & 0,95 & 2.974 & 4,41 & 5.695 & 1,61 \\
BALEARES & 2.059 & 0,72 & 1.109 & 1,64 & 3.168 & 0,89 \\
CANARIAS & 4.913 & 1,71 & 1.780 & 2,64 & 6.693 & 1,89 \\
CANTABRIA & 1.220 & 0,43 & 969 & 1,44 & 2.189 & 0,62 \\
CASTILLA-LA MANCHA & 11.085 & 3,86 & 4.729 & 7,01 & 15.814 & 4,46 \\
CASTILLA Y LEÓN & 9.527 & 3,32 & 2.393 & 3,55 & 11.920 & 3,36 \\
CATALUÑA & 37.752 & 13,16 & 6.142 & 9,11 & 43.894 & 12,39 \\
COM. VALENCIANA & 48.149 & 16,78 & 5.049 & 7,49 & 53.198 & 15,01 \\
EXTREMADURA & 5.561 & 1,94 & 1.398 & 2,07 & 6.959 & 1,96 \\
GALICIA & 8.530 & 2,97 & 3.113 & 4,62 & 11.643 & 3,29 \\
MADRID & 14.207 & 4,95 & 7.809 & 11,58 & 22.016 & 6,21 \\
MURCIA & 17.255 & 6,01 & 4.563 & 6,77 & 21.818 & 6,16 \\
NAVARRA & 6.658 & 2,32 & 2.481 & 3,68 & 9.139 & 2,58 \\
PAÍS VASCO & 55.125 & 19,21 & 7.233 & 10,72 & 62.358 & 17,60 \\
RIOJA (LA) & 1.519 & 0,53 & 185 & 0,27 & 1.704 & 0,48 \\
CEUTA Y MELILLA & 580 & 0,20 & 94 & 0,14 & 674 & 0,19 \\
\hline TOTAL & $\mathbf{2 8 6 . 9 1 2}$ & 100 & 67.445 & 100 & 354.357 & 100 \\
\hline
\end{tabular}

$\left(^{*}\right)$ Incluye trabajadores del régimen general y trabajadores autónomos.

FUENTE: Elaboración propia. Datos: Ministerio de Empleo y Seguridad Social (2012). Fichero de Códigos de Cuentas de Cotización en la Seguridad Social. DG del Trabajo Autónomo, de la Economía Social y de la Responsabilidad Social de las Empresas.

Las Cooperativas andaluzas con un total de 53.639 empleos registrados en 2012, sitúan a Andalucía con un 18,70\% en segunda posición nacional (sólo por detrás de País Vasco con 55.125 empleos), sobre un total de 286.912 empleos registrados. Con 13.698 empleos registrados en Sociedades Laborales, $20,31 \%$ del total nacional, Andalucía es la comunidad que mayor empleo registra de España, sobre un total 67.445 empleos registrados por las sociedades laborales españolas a finales de 2012. 


\section{LAS SOCIEDADES COOPERATIVAS Y LABORALES COMO ARTÍFICES DEL EMPRENDIMIENTO EMPRESARIAL. ANÁLISIS COMPARATIVO DEL PERFIL DEL EMPRENDEDOR DE AMBAS FIGURAS EN EL CONTEXTO DE ANDALUCÍA}

Si analizamos el empleo registrado por las empresas de Economía Social en España, Andalucía con 67.337 empleos sobre un total de 354.357 registra el 19\% del total, lo que la posiciona como la primera en el Ranking nacional, seguida por el País Vasco $(17,60 \%)$ y la Comunidad Valenciana $(15,01 \%)$. Las tres comunidades concentran el $51,61 \%$ de todo el empleo del sector, lo que supone más de la mitad del empleo nacional registrado a 31 de diciembre de 2012 (CEPES-Andalucía, 2012).

\section{Gráfico 2. Distribución del Empleo en Cooperativas y Sociedades Laborales por Comunidad Autónoma en situación de alta en la Seguridad Social a 31/12/2012}

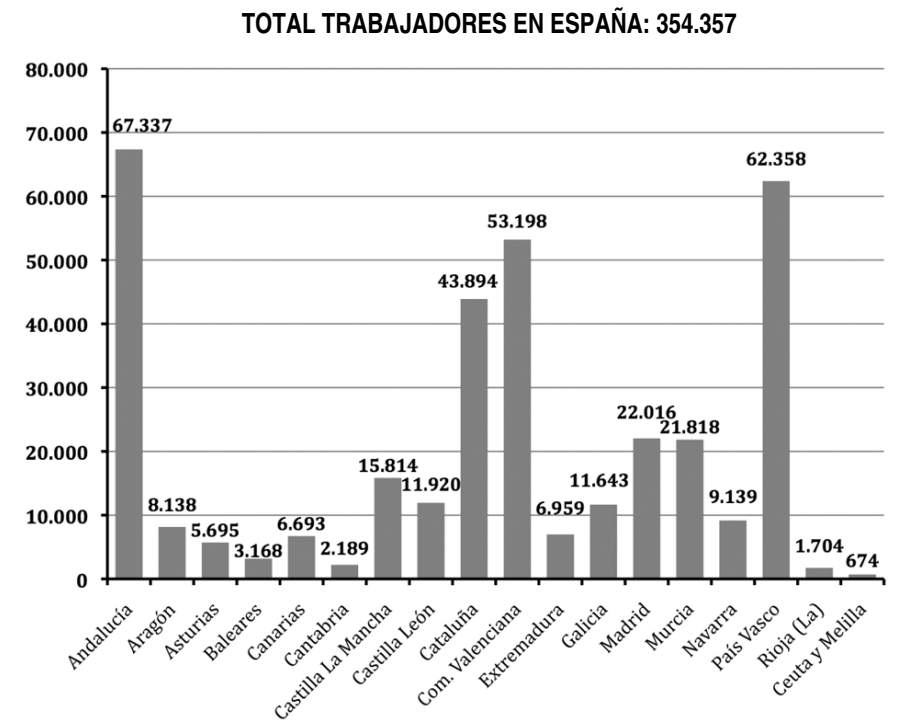

FUENTE: Elaboración propia. Datos: Ministerio de Empleo y Seguridad Social (2012). Fichero de Códigos de Cuentas de Cotización en la Seguridad Social. DG del Trabajo Autónomo, de la Economía Social y de la Responsabilidad Social de las Empresas.

\subsection{La creación de empresas de Economía Social en Andalucía}

Si analizamos la evolución de las Cooperativas y Sociedades Laborales inscritas en los registros de Cooperativas y de Sociedades Laborales de Andalucía entre 2003 y 2012, podemos observar el ritmo de creación de ambos tipos de sociedades en la Comunidad de Andalucía durante la última década (véanse cuadro $n^{\circ} 3$ y gráfico $n^{\circ} 3$ ). 
Cuadro 3. Creación de Cooperativas y Sociedades Laborales en Andalucía. Distribución por tipo de empresa y provincia en el período $2003-2012$

\begin{tabular}{|c|c|c|c|c|c|c|c|c|c|c|}
\hline & & ALMERÍA & CÁDIZ & CÓRDOBA & GRANADA & HUELVA & JAÉN & MÁLAGA & SEVILLA & ANDALUCÍA \\
\hline \multirow[t]{2}{*}{2003} & COOP & 60 & 70 & 78 & 84 & 60 & 64 & 114 & 192 & 722 \\
\hline & S. LAB & 180 & 160 & 148 & 148 & 158 & 141 & 300 & 285 & 1.520 \\
\hline \multirow[t]{2}{*}{2004} & $\mathrm{COOP}$ & 52 & 61 & 58 & 64 & 34 & 45 & 126 & 147 & 587 \\
\hline & S. LAB & 161 & 135 & 135 & 130 & 109 & 128 & 273 & 246 & 1.317 \\
\hline \multirow[t]{2}{*}{2005} & $\mathrm{COOP}$ & 56 & 27 & 40 & 45 & 37 & 45 & 75 & 94 & 419 \\
\hline & S. LAB & 124 & 131 & 98 & 90 & 116 & 78 & 193 & 197 & 1.027 \\
\hline \multirow[t]{2}{*}{2006} & COOP & 18 & 12 & 32 & 18 & 9 & 18 & 27 & 36 & 170 \\
\hline & S. LAB & 66 & 55 & 75 & 71 & 69 & 42 & 134 & 128 & 640 \\
\hline \multirow[t]{2}{*}{2007} & $\mathrm{COOP}$ & 22 & 6 & 35 & 26 & 11 & 30 & 43 & 58 & 231 \\
\hline & S. LAB & 58 & 68 & 80 & 63 & 75 & 58 & 163 & 108 & 673 \\
\hline \multirow[t]{2}{*}{2008} & $\mathrm{COOP}$ & 17 & 11 & 39 & 33 & 16 & 13 & 29 & 52 & 210 \\
\hline & S. LAB & 39 & 38 & 49 & 43 & 44 & 32 & 103 & 68 & 416 \\
\hline \multirow[t]{2}{*}{2009} & $\mathrm{COOP}$ & 22 & 16 & 32 & 29 & 14 & 14 & 27 & 45 & 199 \\
\hline & S. LAB & 19 & 17 & 39 & 24 & 29 & 29 & 111 & 62 & 330 \\
\hline \multirow[t]{2}{*}{2010} & $\mathrm{COOP}$ & 24 & 17 & 10 & 36 & 17 & 8 & 24 & 40 & 176 \\
\hline & S. LAB & 28 & 28 & 46 & 34 & 56 & 29 & 64 & 46 & 331 \\
\hline \multirow[t]{2}{*}{2011} & $\mathrm{COOP}$ & 9 & 13 & 20 & 24 & 13 & 10 & 32 & 42 & 163 \\
\hline & S. LAB & 25 & 29 & 33 & 26 & 25 & 26 & 73 & 59 & 296 \\
\hline \multirow[t]{2}{*}{2012} & $\mathrm{COOP}$ & 18 & 20 & 13 & 26 & 8 & 15 & 29 & 47 & 176 \\
\hline & S. LAB & 21 & 21 & 36 & 25 & 27 & 28 & 49 & 40 & 247 \\
\hline \multicolumn{2}{|c|}{$2003-\mathrm{COOP}$} & 298 & 253 & 357 & 385 & 219 & 262 & 526 & 753 & 3.053 \\
\hline \multirow{2}{*}{\multicolumn{2}{|c|}{\begin{tabular}{|ll}
2012 & S. LAB \\
\end{tabular}}} & 721 & 682 & 739 & 654 & 708 & 591 & 1.463 & 1.239 & 6.797 \\
\hline & & 1.019 & 935 & 1.096 & 1.039 & 927 & 853 & 1.989 & 1.992 & 9.850 \\
\hline
\end{tabular}

FUENTE: Elaboración propia. Bases de Datos: Registro de Cooperativas de Andalucía y Registro Administrativo de Sociedades Laborales de Andalucía (R@sIA).

En relación a la distribución de empresas constituidas en Andalucía según su forma jurídica, podemos observar que un $30,99 \%$ corresponde a Cooperativas y un $69,01 \%$ a Sociedades Laborales en el período 2003-2012. La mayor concentración de empresas de Economía Social registradas se da en Sevilla con el $20,24 \%$ y Málaga con el $20,21 \%$, provincias que en conjunto concentran más del $40,45 \%$ del total. 


\section{LAS SOCIEDADES COOPERATIVAS Y LABORALES COMO ARTÍFICES DEL EMPRENDIMIENTO EMPRESARIAL. ANÁLISIS COMPARATIVO DEL PERFIL DEL EMPRENDEDOR DE AMBAS FIGURAS EN EL CONTEXTO DE ANDALUCÍA}

Tal y como se observa en la figura (gráfico $n^{0} 3$ ), la evolución conjunta de Cooperativas y Sociedades Laborales creadas en Andalucía (empresas ECSO) se caracteriza por una tendencia negativa, confirmando el impacto de la crisis actual. Dicha tendencia sólo se invierte con un ligero incremento en 2007 (11,6\%), continuando su tendencia negativa descendente hasta alcanzar su valor mínimo en el último año de la serie 2012.

\section{Gráfico 3. Evolución del número de Cooperativas y Sociedades Laborales registradas en Andalucía en el período 2003-2012}



FUENTE: Elaboración propia. Bases de Datos: Registro de Cooperativas de Andalucía y Registro Administrativo de Sociedades Laborales de Andalucía (R@sIA).

El empleo registrado entre 2003-2012 por Cooperativas y Sociedades Laborales de nueva creación en Andalucía asciende a 40.336 socios trabajadores, de los cuales $22.797(56,52 \%)$ son generados por Cooperativas y $17.539(43,48 \%)$ por Sociedades Laborales. La distribución de los socios trabajadores según sexos, es de un $63,19 \%$ de socios varones y un $36,81 \%$ de socios mujeres en Cooperativas, y en el caso de Sociedades Laborales un $70,98 \%$ de socios varones y $29,02 \%$ de socios mujeres.

Si analizamos la evolución del número de socios trabajadores registrados en las Sociedades Cooperativas Andaluzas en 2003-2012 (gráfico $\mathrm{n}^{\circ}$ 4), se puede apreciar una tendencia negativa con grandes oscilaciones periódicas interanuales, experimentando leves incrementos en los ejercicios 2005 (1,89\%), 2007 (12,14\%), 2008 (30,30\%), y un gran aumento en 2011 (219,44\%), debido principalmente a los procesos de fusión de sociedades cooperativas del sector oleícola acontecidos en las provincias de Córdoba y Sevilla, con el objetivo de lograr mayor competitividad y rentabilidad en un mercado cada vez más globalizado. Si realizamos el mismo análisis en las Sociedades Laborales Andaluzas, se puede observar una tendencia negativa más acusada, experimentando sólo un ligero incremento en el ejercicio 2007 (4,37\%). 


\section{Gráfico 4. Evolución del empleo de socios trabajadores iniciales registrados en Cooperativas y Sociedades Laborales de Andalucía en el período 2003-2012}

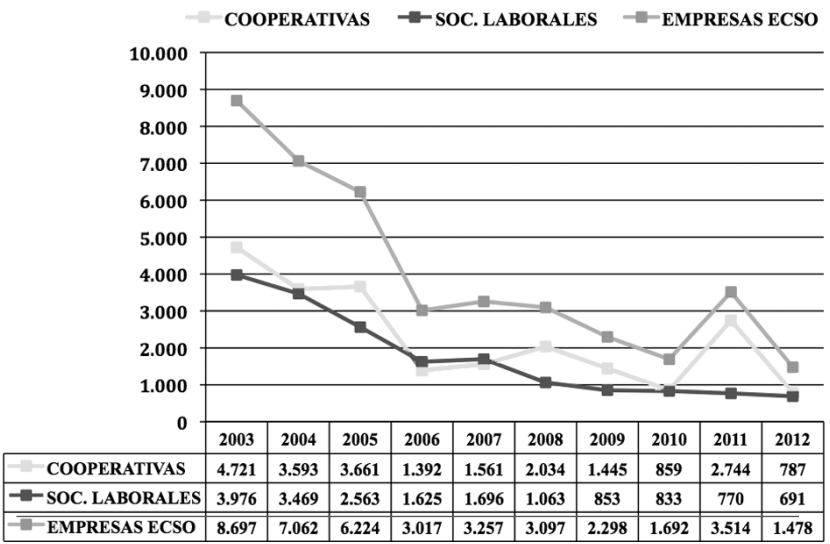

FUENTE: Elaboración propia. Bases de Datos: Registro de Cooperativas de Andalucía y Registro Administrativo de Sociedades Laborales de Andalucía (R@sIA).

La figura anterior (gráfico $\mathrm{n}^{\circ} 4$ ) muestra la evolución del empleo en las principales empresas de Economía Social (empresas ECSO) de Andalucía, reflejando un continuo descenso del empleo registrado hasta alcanzar 2007, año que registra un ligero aumento (7,95\%), continuando la tendencia negativa en los años siguientes hasta llegar al ejercicio 2011, año en que se produce el mayor crecimiento del empleo registrado (207,68\%), favorecido por el aumento significativo del empleo cooperativo. Dicha tendencia alcanza su valor mínimo de empleo registrado en el último año 2012, reiterando el impacto negativo de la crisis vigente en la generación de empleo.

\section{3.- Análisis del perfil de los emprendedores de cooperativas y sociedades laborales de Andalucía. Estudio empírico: emprendedores en Centros de Apoyo al Desarrollo Empresarial}

\subsection{Población objeto de estudio y determinación de la muestra}

La población objeto de estudio está compuesta por empresas de Economía Social, Cooperativas y Sociedades Laborales (SLL y SAL), adscritas al Programa de la Red Territorial de Apoyo a Emprendedores entre el período 2003 y 2012. 


\section{LAS SOCIEDADES COOPERATIVAS Y LABORALES COMO ARTÍFICES DEL EMPRENDIMIENTO EMPRESARIAL. ANÁLISIS COMPARATIVO DEL PERFIL DEL EMPRENDEDOR DE AMBAS FIGURAS EN EL CONTEXTO DE ANDALUCÍA}

El término adscripción está referido a las sociedades que hayan recibido servicios de apoyo a la creación y/o consolidación empresarial, en las Escuelas de Empresas y/o en los Centros de Apoyo al Desarrollo Empresarial, que estén o hayan sido incluidas en el Programa como "empresas integradas" o como "empresas asociadas", según la calificación del Programa Andaluz para el Fomento de la Economía Social "PAFES" (De Pablo y Uribe, 2009).

La Red Territorial de Apoyo a Emprendedores es un instrumento de la Junta de Andalucía puesto al servicio de las personas emprendedoras y empresas de la comunidad autónoma de Andalucía. Gestionada por Andalucía Emprende, Fundación Pública Andaluza esta red cuenta en la actualidad con más de 200 Centros de Apoyo al Desarrollo Empresarial (CADE), distribuidos en 37 zonas CADE, desde donde un cualificado equipo técnico de especialistas en las distintas materias empresariales, presta servicios de apoyo a la creación y consolidación de empresas y empleo, dando cobertura al 100\% de los municipios andaluces (Andalucía Emprende, 2013).

La base de datos del estudio se ha obtenido de la Plataforma Tecnológica de Andalucía Emprende utilizada por la Red Territorial de Apoyo a Emprendedores para completar el proceso de adscripción, sometida a las normas de calidad ISO 9001:2000 y certificado por AENOR (De Pablo y Uribe, 2009).

La base de datos incluye un total de 1.865 empresas de Economía Social creadas en las ocho provincias de Andalucía. Las 1.865 empresas que integran la muestra tienen fecha de constitución registral comprendida entre el 01/01/2003 y el 31/12/2012. La muestra contiene a 7.224 emprendedores y se distribuye en 6.289 socios trabajadores y 935 socios capitalistas o inversores (véase Martín, Lejarriaga e Iturrioz, 2007).

Las 1.865 empresas de Economía Social que componen la muestra objeto de análisis se distribuyen en 745 Cooperativas (39,95\%) y 1.120 Sociedades Laborales $(60,05 \%)$, que generan un total de 6.289 nuevos empleos de socios trabajadores.

\subsection{Recolección de datos y ficha técnica}

La recopilación de los datos que integran la muestra tuvo lugar entre el 1 de enero 2003 y el 31 de diciembre de 2012. Se obtiene una muestra de 1.865 empresas de Economía Social, que representa el $18,93 \%$ del total de Cooperativas y Sociedades Laborales (9.850) creadas en Andalucía en el período de referencia 2003-2012 (véase cuadro $n^{\circ} 4$ ). 


\section{FICHA TÉCNICA}

\begin{tabular}{|c|c|}
\hline Universo & 9.850 empresas de Economía Social \\
\hline Ámbito geográfico & Andalucía \\
\hline Tamaño de la Muestra & $\begin{array}{l}1865 \text { empresas de Economía Social de Andalucía: Cooperativas y Sociedades } \\
\text { Laborales, adscritas al Programa Red Territorial de Apoyo a Emprendedores }\end{array}$ \\
\hline Metodología & $\begin{array}{l}\text { Recepción de justificante de inscripción de la empresa en el registro correspondiente } \\
\text { y grabación por los Centros de Apoyo al Desarrollo Empresarial (CADE) }\end{array}$ \\
\hline Herramienta & Aplic@: Plataforma Tecnológica Andalucía Emprende \\
\hline Error Muestral $\left({ }^{\star}\right)(p=q=0,5)$ & $\pm 2,043 \%$ \\
\hline Nivel de confianza & $95 \%$ \\
\hline Período de recogida de datos & 01 Enero 2003 - 31 Diciembre 2012 \\
\hline
\end{tabular}

$\left(^{*}\right)$ El cálculo del error muestral se ha realizado para poblaciones finitas: $p=q=0,5$.

FUENTE: Elaboración propia.

A continuación se analiza la proporción existente entre los datos obtenidos en la muestra y el universo poblacional de referencia, según el tipo de empresa de Economía Social creada en Andalucía en el período 2003-2012.

\section{Cuadro 4. Representación de los datos muestrales en el universo poblacional. Distribución de las empresas según su forma jurídica en el período 2003-2012}

\begin{tabular}{|l|cccc|}
\hline & $\begin{array}{c}\text { Datos } \\
\text { Muestra }\end{array}$ & $\%$ & Datos & Universo \\
\hline COOP. 1er. Grado & 745 & 39,95 & 3.010 & 30,56 \\
COOP. 2do ó + Grado & 0 & 0 & 43 & 0,44 \\
S.L.L. & 1.115 & 59,79 & 6.760 & 68,63 \\
S.A.L. & 5 & 0,27 & 37 & 0,38 \\
\hline TOTAL & 1.865 & 100 & 9.850 & 100 \\
\hline
\end{tabular}

FUENTE: Elaboración propia. Datos a partir de la muestra obtenida en los CADE y de bases de datos de los Registros de Cooperativas y Sociedades Laborales de Andalucía (R@sIA). 


\section{LAS SOCIEDADES COOPERATIVAS Y LABORALES COMO ARTÍFICES DEL EMPRENDIMIENTO EMPRESARIAL. ANÁLISIS COMPARATIVO DEL PERFIL DEL EMPRENDEDOR DE AMBAS FIGURAS EN EL CONTEXTO DE ANDALUCÍA}

\subsection{Perfil del emprendedor en Economía Social}

\subsubsection{Según tipo de sociedad}

La forma jurídica de la Economía Social más representativa de las empresas adscritas al Programa Red Territorial de Apoyo a Emprendedores en Andalucía desde el año 2003 hasta el 2012 (gráfico n 5) es la Sociedad Limitada Laboral (SLL).

\section{Gráfico 5. Creación de empresas en Andalucía según su forma jurídica en el período $2003-2012$}

EMPRESAS DE ECONOMÍA SOCIAL INCUBADAS EN LOS CADE

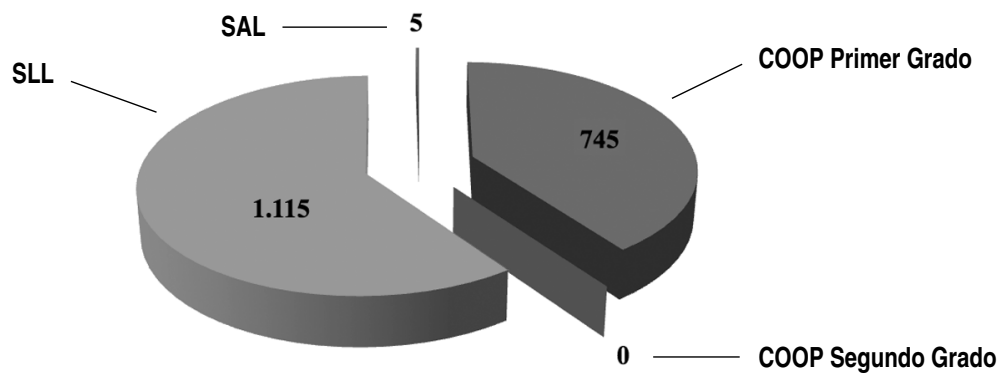

FUENTE: Elaboración propia a partir de datos de la muestra obtenida en los CADE.

Si analizamos el porcentaje de empresas adscritas pertenecientes a la Economía Social (Cooperativas y Sociedades Laborales), podemos observar que las Sociedades Limitadas Laborales representan aproximadamente el $60 \%$ en la muestra, confirmando su predominio generalizado en la región de Andalucía durante el período de referencia 2003-2012 (véase cuadro n 4).

La muestra de 1.865 empresas de Economía Social obtenida a partir de la base de datos de empresas incubadas en los CADEs de Andalucía en el período 2003-2012, se distribuye en 745 Cooperativas $(39,95 \%)$ y 1.120 Sociedades Laborales $(60,05 \%)$. La provincia andaluza que mayor número de empresas de Economía Social concentra es Sevilla, con un total de 301 (16,14\%), seguida de Málaga con $271(14,53 \%)$, Jaén con $259(13,89 \%)$, Granada con $223(11,96 \%)$, Córdoba con $219(11,74 \%)$, Huelva con $215(11,53 \%)$, Almería con 193 (10,35\%) y por último Cádiz con 184 (9,87\%). 


\section{Gráfico 6. Distribución de empresas de Economía Social de la muestra, según forma jurídica en el período 2003 - 2012}

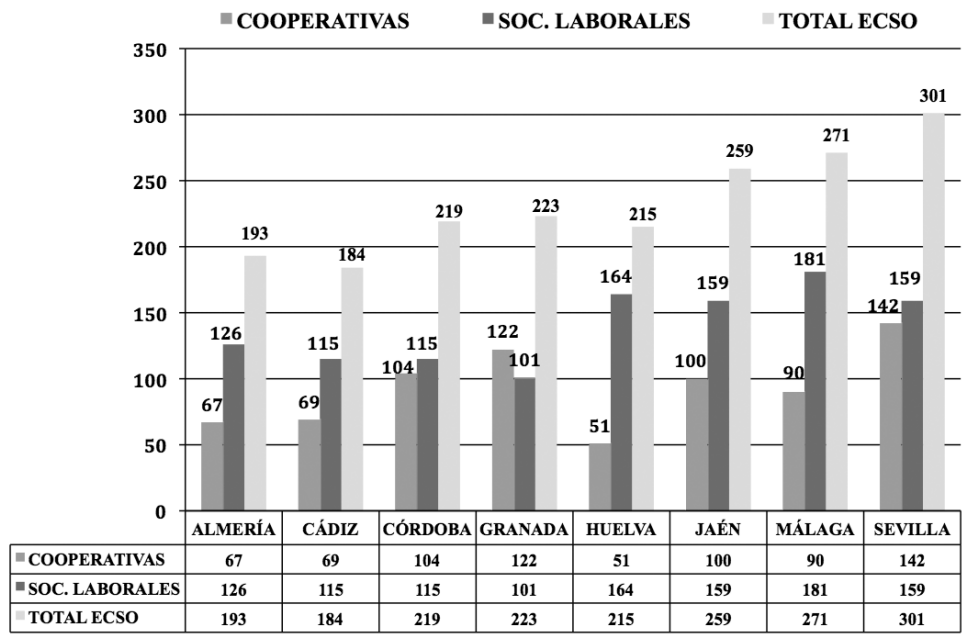

FUENTE: Elaboración propia. Datos a partir de la muestra obtenida en los CADE.

La provincia de Andalucía con mayor número de Cooperativas de nueva creación en la muestra es Sevilla con $142(19,06 \%)$, Granada con $122(16,38 \%)$ y Córdoba con 104 (13,96\%). En el caso de las Sociedades Laborales, la provincia de Málaga con un total de $181(16,16 \%)$, Huelva con 164 $(14,64 \%)$, Sevilla y Jaén, ambas con $159(14,20 \%)$.

\subsubsection{Según sexo}

Los socios trabajadores varones son mayoría con el $63,97 \%$, mientras que las socias trabajadoras mujeres representan el $36,03 \%$ en el total de las empresas de Economía Social constituidas en Andalucía en el período 2003-2012, con mayor participación en Cooperativas (37,62\%) que en Sociedades Laborales (35,16\% en Sociedades Limitadas Laborales y 13,89\% en Sociedades Anónimas Laborales). 


\section{Cuadro 5. Distribución de socios trabajadores de empresas de Economía Social de nueva creación en el período 2003-2012 según sexo}

\begin{tabular}{|l|cccccc|}
\hline SEXO & Varones & $\%$ & Mujeres & $\%$ & TOTAL & $\%$ \\
\hline COOP & 1.587 & 62,38 & 957 & 37,62 & 2.544 & 100 \\
SAL & 31 & 86,11 & 5 & 13,89 & 36 & 100 \\
SLL & 2.405 & 64,84 & 1.304 & 35,16 & 3.709 & 100 \\
TOTAL & 4.023 & 63,97 & 2.266 & 36,03 & 6.289 & 100 \\
\hline
\end{tabular}

FUENTE: Elaboración propia. Datos a partir de la muestra obtenida en los CADE.

La distribución de la submuestra por sexo de los emprendedores de Economía Social confirma la distribución general según sexo seguida en Andalucía durante 2003-2012, según la cual los varones participan en un $63,19 \%$ en la constitución de Cooperativas, frente a un $36,81 \%$ de las mujeres; en el caso de las Sociedades Anónimas Laborales (SAL) los varones son mayoría con un 76,43\%, mientras que las mujeres sólo participan con el 23,57\%; y en el caso de Sociedades Limitadas Laborales (SLL) se obtiene una distribución muy similar, al ser mayoritarios los varones con el 70,97\% frente al $29,03 \%$ de participación por parte de las mujeres.

Este comportamiento es muy diferente al registrado en la población ocupada española, que muestra una presencia de la mujer que aumenta progresivamente. Teniendo en cuenta lo anterior, se puede afirmar que las mujeres están en la actualidad menos representadas en el conjunto de emprendedores de la Economía Social andaluza, destacando su creciente importancia y participación. En definitiva, se puede señalar que la incorporación de la mujer a las actividades emprendedoras ha sido más tardía que su participación como asalariada en el mercado laboral (Congregado et al., 2008).

\subsubsection{Según edad}

La moda de la distribución o edad de mayor frecuencia a la hora de emprender, teniendo en cuenta la muestra disponible de 7.224 emprendedores, es 30 años; la mediana representativa del valor central del conjunto de edades es 34 años; y la media aritmética o valor promedio de edades es 35,18 años, con una desviación estándar (o desviación típica) de 10,20 años (véase gráfico $n^{\circ} 7$ ).

La edad promedio muestral ( 35,18 años) de los emprendedores de Cooperativas y Sociedades Laborales incubadas en los CADEs de Andalucía es muy inferior a la media del conjunto de emprendedores españoles (44 años). 


\section{Gráfico 7. Distribución de emprendedores de empresas de Economía Social según forma jurídica en el período 2003-2012 por grupos de edad}



FUENTE: Elaboración propia. Datos a partir de la muestra obtenida en los CADE.

En 2006, la media de edad del conjunto de emprendedores españoles se situaba en los 44 años, rasgo que muestra una relativa estabilidad a lo largo de los últimos treinta años, constatándose también que ha tenido lugar un cierto rejuvenecimiento a lo largo del período considerado. Durante las últimas tres décadas, el colectivo de emprendedores en la economía española ha experimentado un progresivo rejuvenecimiento, aunque sigue manteniendo una mayor experiencia que el trabajador ocupado promedio (38,9 años). En 1977, la edad media de los emprendedores era de 45,6 años, nivel a partir del cual se produjo un paulatino descenso hasta finales de los ochenta y una estabilización que se ha mantenido desde entonces cercana a los 44 años (Congregado et al., 2008).

Según los datos disponibles más recientes de la Economía Social en Andalucía (véase Informe Estadístico de la Economía Social Andaluza, II trimestre 2014; CEPES-Andalucía, 2014), el 43,5\% de trabajadores de la Economía Social andaluza tienen entre 25 y 39 años, por lo que podemos concluir que los jóvenes son los principales generadores de empleo en el sector de la Economía Social andaluza.

Por lo que respecta a los cambios registrados a lo largo del tiempo, el patrón general de menor peso de los menores de 25 años y mayores de 65 en la economía española, es común a todos los tipos de emprendedores durante las tres décadas analizadas (Congregado et al., 2008).

\subsubsection{Según formación}

El $51 \%$ de la población española entre 25 y 64 años tiene estudios postobligatorios, secundarios o superiores, un porcentaje muy alejado del valor medio de la OCDE y la UE- 19 ( $71 \%$ y $72 \%$ respec- 


\section{LAS SOCIEDADES COOPERATIVAS Y LABORALES COMO ARTÍFICES DEL EMPRENDIMIENTO EMPRESARIAL. ANÁLISIS COMPARATIVO DEL PERFIL DEL EMPRENDEDOR DE AMBAS FIGURAS EN EL CONTEXTO DE ANDALUCÍA}

tivamente). El atraso educativo que estos datos reflejan se debe a que sólo hay un $22 \%$ de la población entre 25 y 64 años cuyos estudios más avanzados corresponden a algún tipo de educación secundaria postobligatoria. Los niveles educativos de las nuevas generaciones son mayores. De los jóvenes entre 25 y 34 años, el 26,3\% tiene estudios de secundaria postobligatoria y el 38,8\% estudios superiores, de modo que un $65 \%$ tiene estudios postobligatorios (Pérez et al., 2011).

En general, se evidencia la progresiva y continua mejora de la formación de los emprendedores españoles en las últimas décadas. Este hecho tiene consecuencias positivas en los propios emprendedores, que ven ampliadas sus probabilidades de acceder a un alto cargo y de obtener mayores retribuciones (Congregado et al., 2008).

A continuación analizamos el nivel o grado de formación reglada alcanzado por los emprendedores andaluces según la forma jurídica de empresa de Economía Social adoptada en el período 20032012 (véase cuadro $n^{\circ} 6$ ).

\section{Cuadro 6. Distribución de emprendedores de empresas de Economía Social de nueva creación en el período 2003-2012 según nivel formativo}

\begin{tabular}{|l|cccccccc|c|}
\hline FORMACIÓN & $\begin{array}{c}\text { Sin } \\
\text { Estudios }\end{array}$ & ESO & FP & BUP & Diplomado & Ingeniería & Licenciado & $\begin{array}{c}\text { No } \\
\text { Consta }\end{array}$ & TOTAL \\
\hline COOP & 288 & 922 & 690 & 366 & 270 & 84 & 343 & 3 & 2.966 \\
SAL & 9 & 15 & 4 & 8 & 3 & 0 & 5 & 0 & 44 \\
SLL & 527 & 1.313 & 699 & 645 & 436 & 118 & 476 & 0 & 4.214 \\
\hline TOTAL & 824 & $\mathbf{2 . 2 5 0}$ & 1.393 & 1.019 & 709 & 202 & 824 & 3 & 7.224 \\
$\%$ & 11,41 & 31,15 & 19,28 & 14,11 & 9,81 & 2,80 & 11,41 & $\mathbf{0 , 0 4}$ & 100 \\
\hline
\end{tabular}

FUENTE: Elaboración propia. Datos a partir de la muestra obtenida en los CADE.

Sólo el 24,02\% de los emprendedores andaluces de Economía Social incluidos en la muestra, conformada en el período 2003-2012 por un total de 7.224 emprendedores (2.966 de Cooperativas, 44 de SAL y 4.214 de SLL), ha cursado estudios superiores en la Universidad, a diferencia del $11,41 \%$ que manifiesta no haber realizado estudios (sin estudios), un $31,15 \%$ ha realizado la Enseñanza Secundaria Obligatoria (ESO o equivalente), el 19,28 de la muestra tiene estudios de Formación Profesional (FP), un $14,11 \%$ de BUP-COU, y sólo en un $0,04 \%$ no consta el nivel formativo alcanzado.

Asimismo, el grupo mayoritario según forma jurídica y formación realizada, corresponde con el $18,18 \%$ de probabilidad al grupo de emprendedores de las Sociedades Limitadas Laborales (SLL) con un grado formativo alcanzado igual o equivalente al de la Enseñanza Secundaria Obligatoria (ESO). 
También es significativo el grupo de emprendedores sin estudios (11,41\%), con idéntica proporción al grupo de emprendedores con licenciatura. Estas diferencias pueden ser muy importantes porque, aunque las investigaciones llevadas a cabo ponen de manifiesto que no es estrictamente necesario disponer de una educación reglada para crear un nuevo negocio, un mayor nivel educativo, y especialmente si se relaciona con el campo de la economía, puede suponer una ventaja de base (García y Wandosell, 2004)

La probabilidad de supervivencia de las empresas de Economía Social depende tanto de sus propias características intrínsecas o endógenas: tamaño inicial, alcance de los costes hundidos, etc. como del elemento humano, es decir, de las características personales y cualificación del emprendedor, que constituye uno de los factores de mayor trascendencia en el éxito de un proyecto empresarial. En este sentido, existe evidencia empírica que muestra que la supervivencia de las empresas depende de factores como: la preparación o formación del empresario, su conocimiento del sector, la experiencia empresarial del emprendedor, etc. (García y Wandosell, 2004).

\subsubsection{Según procedencia regional}

Para analizar la procedencia del emprendedor de Economía Social en Andalucía, la muestra objeto de análisis configurada por 1.865 empresas y 7.224 emprendedores, se estructura según provincias de origen, agrupando a los emprendedores según la forma jurídica seleccionada y la provincia de origen en el momento de crear la empresa, lo cual permitirá observar la distribución geográfica regional en la creación de empresas de Economía Social en Andalucía durante el período 2003-2012, según tipo de empresa y origen de los emprendedores (véase cuadro $\mathrm{n}^{0} 7$ ).

Según la muestra de referencia obtenida en los Centros de Apoyo al Desarrollo Empresarial (CADEs) de Andalucía en el período 2003-2012, la provincia andaluza que mayor número de emprendedores de Economía Social concentra es Sevilla, con un total de $1.212(16,78 \%)$, seguida de Jaén con $1.008(13,95 \%)$, Málaga con $1.005(13,91 \%)$, Granada con $1.000(13,84 \%)$, Huelva con 825 (11,42\%), Córdoba con 815 (11,28\%), Almería con $726(10,05 \%)$ y, por último, Cádiz con $633(8,76 \%)$.

La forma jurídica con mayor número de emprendedores de Economía Social es la Sociedad Limitada Laboral (SLL) con 4.214 (58,33\%), seguida de la Cooperativa (COOP) con $2.966(41,06 \%)$, y la Sociedad Anónima Laboral (SAL) con 44 (0,61\%). 


\section{Cuadro 7. Distribución de emprendedores de empresas de Economía Social de nueva creación en el período 2003-2012 según procedencia regional}

\begin{tabular}{|l|cccccccc|}
\hline PROCEDENCIA & COOP & $\%$ & SLL & $\%$ & SAL & $\%$ & TOTAL & $\%$ \\
\hline ALMERÍA & 272 & 9,17 & 454 & 10,77 & 0 & 0 & $\mathbf{7 2 6}$ & 10,05 \\
CÁDIZ & 228 & 7,69 & 405 & 9,61 & 0 & 0 & 633 & $\mathbf{8 , 7 6}$ \\
CÓRDOBA & 407 & 13,72 & 389 & 9,23 & 19 & 43,18 & $\mathbf{8 1 5}$ & 11,28 \\
GRANADA & 642 & 21,65 & 355 & 8,42 & 3 & 6,82 & 1.000 & 13,84 \\
HUELVA & 202 & 6,81 & 623 & 14,78 & 0 & 0 & 825 & 11,42 \\
JAÉN & 373 & 12,58 & 630 & 14,95 & 5 & 11,36 & 1.008 & 13,95 \\
MÁLAGA & 333 & 11,23 & 672 & 15,95 & 0 & 0 & 1.005 & 13,91 \\
SEVILLA & 509 & 17,16 & 686 & 16,28 & 17 & 38,64 & 1.212 & 16,78 \\
\hline ANDALUCÍA & $\mathbf{2 . 9 6 6}$ & $\mathbf{1 0 0}$ & $\mathbf{4 . 2 1 4}$ & $\mathbf{1 0 0}$ & 44 & 100 & $\mathbf{7 . 2 2 4}$ & 100 \\
$\%$ & 41,06 & & $\mathbf{5 8 , 3 3}$ & & $\mathbf{0 , 6 1}$ & & 100 & \\
\hline
\end{tabular}

FUENTE: Elaboración propia. Datos a partir de la muestra obtenida en los CADE.

Atendiendo a la distribución provincial de emprendedores de Sociedades Limitadas Laborales (SLL) en Andalucía, Sevilla es con un total de $686(16,28 \%)$ la provincia que mayor número de emprendedores concentra, le sigue Málaga con 672 (15,95\%), Jaén con 630 (14,95\%), Huelva con 623 (14,78\%), Almería con $454(10,77 \%)$, Cádiz con 405 (9,61\%), Córdoba con 389 (9,23\%), y la provincia de Granada con $355(8,42 \%)$.

Si analizamos la distribución provincial de los emprendedores de Cooperativas (COOP) andaluzas, Granada es la provincia que mayor número de emprendedores comprende, con un total de 642 $(21,65 \%)$, seguida de Sevilla con 509 cooperativistas (17,16\%), Córdoba con $407(13,72 \%)$, Jaén con $373(12,58 \%)$, Málaga con $333(11,23 \%)$, Almería con $272(9,17 \%)$, Cádiz con $228(7,69 \%)$, y por último la provincia de Huelva con $202(6,81 \%)$ emprendedores de cooperativas.

En cuanto a los emprendedores de Sociedades Anónimas Laborales (SAL), Córdoba es la provincia con un mayor número de emprendedores, con un total de $19(43,18 \%)$, seguida de Sevilla con $17(38,64 \%)$, Jaén con $5(11,36 \%)$ y Granada con $3(6,82 \%)$.

\subsubsection{Según el sector económico de actividad}

El sector económico más representativo de la muestra objeto de análisis es el terciario o servicios con un total de $966(51,80 \%)$ empresas de Economía Social (ECSO), seguido por el sector industria con $882(47,29 \%)$, y en último lugar, el sector primario con sólo 17 (0,91\%) empresas. Esta distribución sectorial viene a reflejar la progresiva mutación de la actividad productiva/económica acaecida en las últimas décadas en la economía regional andaluza, caracterizada por un significativo cambio en el 
modelo productivo motivado por el continuo trasvase desde los sectores económicos tradicionales primario y secundario hacia el sector terciario o servicios, en paralelo al continuo proceso de terciarización de la economía nacional española (véase cuadro $\mathrm{n}^{\circ} 8$ ).

\section{Cuadro 8. Distribución de las empresas de Economía Social de nueva creación en el período $2003-2012$ según sector de actividad}

\begin{tabular}{|c|c|c|c|c|c|c|c|c|c|}
\hline SECTOR & $\begin{array}{c}\text { FORMA } \\
\text { JURÍDICA }\end{array}$ & PRIMARIO & $\%$ & SECUNDARIO & $\%$ & TERCIARIO & $\%$ & TOTAL & $\%$ \\
\hline \multirow[t]{3}{*}{ ALMERÍA } & $\mathrm{COOP}$ & 0 & 0 & 32 & 10,13 & 35 & 8,33 & 67 & 8,99 \\
\hline & S. LAB & 0 & 0 & 57 & 10,07 & 69 & 12,64 & 126 & 11,25 \\
\hline & ECSO & 0 & 0 & 89 & 10,09 & 104 & 10,77 & 193 & 10,35 \\
\hline \multirow[t]{3}{*}{ CÁDIZ } & $\mathrm{COOP}$ & 0 & 0 & 36 & 11,39 & 33 & 7,86 & 69 & 9,26 \\
\hline & S. LAB & 1 & 12,50 & 65 & 11,48 & 49 & 8,97 & 115 & 10,27 \\
\hline & ECSO & 1 & 5,88 & 101 & 11,45 & 82 & 8,49 & 184 & 9,87 \\
\hline \multirow[t]{3}{*}{ CÓRDOBA } & $\mathrm{COOP}$ & 1 & 11,11 & 59 & 18,67 & 44 & 10,48 & 104 & 13,96 \\
\hline & S. LAB & 1 & 12,50 & 64 & 11,31 & 50 & 9,16 & 115 & 10,27 \\
\hline & ECSO & 2 & 11,76 & 123 & 13,95 & 94 & 9,73 & 219 & 11,74 \\
\hline \multirow[t]{3}{*}{ GRANADA } & COOP & 4 & 44,44 & 42 & 13,29 & 76 & 18,10 & 122 & 16,38 \\
\hline & S. LAB & 1 & 12,50 & 47 & 8,30 & 53 & 9,71 & 101 & 9,02 \\
\hline & ECSO & 5 & 29,41 & 89 & 10,09 & 129 & 13,35 & 223 & 11,96 \\
\hline \multirow[t]{3}{*}{ HUELVA } & COOP & 1 & 11,11 & 23 & 7,28 & 27 & 6,43 & 51 & 6,85 \\
\hline & S. LAB & 1 & 12,50 & 78 & 13,78 & 85 & 15,57 & 164 & 14,64 \\
\hline & ECSO & 2 & 11,76 & 101 & 11,45 & 112 & 11,59 & 215 & 11,53 \\
\hline \multirow[t]{3}{*}{ JAÉN } & $\mathrm{COOP}$ & 0 & 0,0 & 43 & 13,61 & 57 & 13,57 & 100 & 13,42 \\
\hline & S. LAB & 3 & 37,50 & 80 & 14,13 & 76 & 13,92 & 159 & 14,20 \\
\hline & ECSO & 3 & 17,65 & 123 & 13,95 & 133 & 13,77 & 259 & 13,89 \\
\hline \multirow[t]{3}{*}{ MÁLAGA } & $\mathrm{COOP}$ & 2 & 22,22 & 38 & 12,03 & 50 & 11,90 & 90 & 12,08 \\
\hline & S. LAB & 0 & 0 & 85 & 15,02 & 96 & 17,58 & 181 & 16,16 \\
\hline & ECSO & 2 & 11,76 & 123 & 13,95 & 146 & 15,11 & 271 & 14,53 \\
\hline \multirow[t]{3}{*}{ SEVILLA } & COOP & 1 & 11,11 & 43 & 13,61 & 98 & 23,33 & 142 & 19,06 \\
\hline & S. LAB & 1 & 12,50 & 90 & 15,90 & 68 & 12,45 & 159 & 14,20 \\
\hline & ECSO & 2 & 11,76 & 133 & 15,08 & 166 & 17,18 & 301 & 16,14 \\
\hline \multirow[t]{3}{*}{ ANDALUCÍA } & COOP & 9 & 52,94 & 316 & 35,83 & 420 & 43,48 & 745 & 39,95 \\
\hline & S. LAB & 8 & 47,06 & 566 & 64,17 & 546 & 56,52 & 1.120 & 60,05 \\
\hline & ECSO & 17 & 0,91 & 882 & 47,29 & 966 & 51,80 & 1.865 & 100 \\
\hline
\end{tabular}

FUENTE: Elaboración propia. Datos a partir de la muestra obtenida en los CADE. 


\section{LAS SOCIEDADES COOPERATIVAS Y LABORALES COMO ARTÍFICES DEL EMPRENDIMIENTO EMPRESARIAL. ANÁLISIS COMPARATIVO DEL PERFIL DEL EMPRENDEDOR DE AMBAS FIGURAS EN EL CONTEXTO DE ANDALUCÍA}

Si analizamos las actividades económicas más representativas de la Economía Social en Andalucía atendiendo a las principales actividades de la Clasificación Nacional de Actividades Económicas CNAE2009, podemos observar (como ya hemos comentado) que servicios es la actividad más representativa con un total de 821 empresas de Economía Social (ECSO), lo que representa el 44,02\% del total de actividades productivas, seguido de la actividad industrial con 495 empresas ECSO, representando el 26,54\%, la construcción con 387 empresas ECSO el 20,75\%, nuevas tecnologías y comunicaciones (NN.TT.) con 145 empresas el 7,77\%, y en último lugar la actividad agrícola con 17 empresas ECSO el $0,91 \%$ del total.

Por provincias, Sevilla es la que mayor número de empresas posee en servicios con un total de 136 empresas de Economía Social (16,57\%), Málaga con 31 empresas (21,38\%) en nuevas tecnologías es la provincia más representativa en esta actividad, Córdoba en industria con 85 empresas (17,17\%), Málaga en la construcción con 67 empresas (17,31\%), y Granada en la agricultura con 5 empresas $(29,41 \%)$.

\section{Gráfico 8. Distribución de actividades económicas de las empresas de Economía Social según forma jurídica en el período 2003-2012}

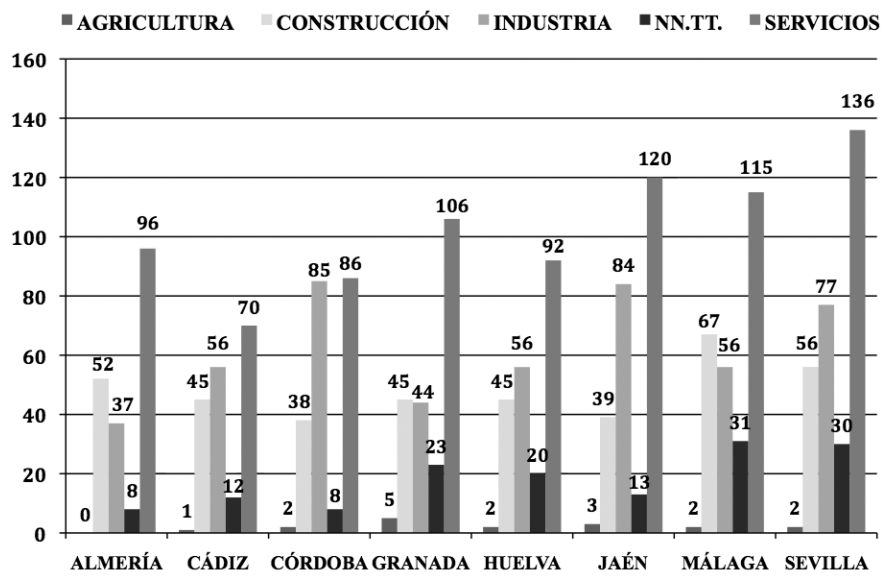

FUENTE: Elaboración propia. Datos a partir de la muestra obtenida en los CADE. 


\section{4.- Conclusiones. Perfil del emprendedor tipo de empresas de Economía Social en la Comunidad de Andalucía}

El perfil tipo del emprendedor de Economía Social en Andalucía, según la muestra base de referencia utilizada en este estudio, es un varón de 30 años (con una mediana de 34 años, media aritmética de 35,18 años y desviación estándar de 10,20 años) socio trabajador y de nacionalidad española, residente en la provincia de Sevilla, con estudios básicos de Enseñanza Secundaria (ESO) o equivalente, que decide emprender una actividad económica empresarial preferentemente en el sector servicios bajo la forma jurídica de Sociedad de responsabilidad Limitada Laboral (SLL).

Dentro del conjunto de emprendedores (7.224) destacan los socios trabajadores (6.289) constituyendo con gran diferencia el principal colectivo (87\%) en el periodo analizado 2003-2012. La progresiva disminución de su presencia en el total del colectivo emprendedor es una muestra más de los cambios que se vienen produciendo en el conjunto de emprendedores en las últimas décadas.

El perfil tipo del emprendedor de Sociedades Cooperativas Andaluzas, según la muestra obtenida de 2.966 emprendedores cooperativistas, es un varón de 30 años (con una mediana de 33 años, media aritmética 34,93 años y desviación estándar de 9,28 años) socio trabajador y de nacionalidad española, con domicilio en la provincia de Granada, estudios de Enseñanza Secundaria (ESO) o equivalente, que decide emprender una actividad empresarial prioritariamente en el sector servicios.

El perfil tipo del emprendedor de Sociedades Laborales en Andalucía, según la muestra obtenida de 4.258 emprendedores, es un varón de 30 años (con una mediana de 34 años, media aritmética 35,36 años y desviación típica de 10,79 años) socio trabajador y de nacionalidad española, con residencia en la provincia de Sevilla, estudios de Enseñanza Secundaria (ESO) o equivalente, que decide emprender una actividad empresarial preferencialmente en el sector terciario o de servicios.

Atendiendo a la perspectiva de género, el perfil de los emprendedores de empresas de Economía Social en Andalucía sigue una distribución similar a la de los emprendedores españoles, predominando mayoritariamente el sexo masculino con el $64 \%$ frente a un $36 \%$ de representación femenina en el período de análisis 2003-2012. Cifras similares se obtienen en diversas investigaciones: Fuentes et al., 2007; Congregado et al., 2008; Fuentes y Sánchez, 2010; Melián, Campos y Sanchís, 2011; Informe "GEM" Global Entrepreneurship Monitor, 2013.

La mayor formación del emprendedor también será clave en el éxito empresarial, beneficiando a las empresas que dirige, dado que se incrementa su productividad. Asimismo, un emprendedor altamente cualificado beneficia al trabajador, que obtiene un mayor rendimiento del aumento de su formación y cualificación profesional. 


\section{LAS SOCIEDADES COOPERATIVAS Y LABORALES COMO ARTÍFICES DEL EMPRENDIMIENTO EMPRESARIAL. ANÁLISIS COMPARATIVO DEL PERFIL DEL EMPRENDEDOR DE AMBAS FIGURAS EN EL CONTEXTO DE ANDALUCÍA}

\section{Bibliografía}

ARANZADI, D. (1992): El arte de ser empresario hoy, Universidad de Deusto, Bilbao.

BALLESTERO, E. (1993): "Economía del autoempleo en las áreas industrializadas: un análisis de perspectivas", CIRIEC-España, Revista de Economía Pública, Social y Cooperativa, 14, 63-78.

BAREA, J. (1991): "La Economía Social en España”, Revista de Economía y Sociología del Trabajo 12, Centro de Publicaciones, Ministerio de Trabajo y Seguridad Social, Madrid, 8-16.

BAREA, J. \& MONZÓN, J.L. (1996): Informe sobre la situación de las cooperativas y las sociedades laborales en España, Editorial CIRIEC-España, Valencia.

BATY, G.B. (1990): Entrepreneurship for the nineties, Prentice Hall, USA, 9-16.

BIRKINSHAW, J., HAMEL, G. \& MOL, M.J. (2008): "Management innovation”, Academy of Management Review, 33:4, 825-845.

BUCKINGHAM, M. (2006): Lo único que usted debe saber... para ser gerente y líder excepcional y alcanzar el éxito duradero, Grupo Editorial Norma, Bogotá D.C.

BURCH, J.G. (1986): Entrepreneurship, Ed. John Wiley and Sons, New York, USA, 493 páginas.

CEPES-ANDALUCÍA (2012): Informes Estadísticos de la Economía Social Andaluza. Cuarto Trimestre de 2012, Edita: Confederación de Entidades para la Economía Social de Andalucía.

CEPES-ANDALUCÍA (2014): Informes Estadísticos de la Economía Social Andaluza. Segundo Trimestre de 2014, Edita: Confederación de Entidades para la Economía Social de Andalucía.

CIRUELA, A.M. (2003): El perfil gerencial en las cooperativas agrarias. Análisis de la gerencia en las cooperativas agrarias de la provincia de Málaga, Universidad de Málaga, Málaga.

CIRUELA, A.M. (2006): "La función directiva en las cooperativas agrarias. Estudio empírico en las sociedades cooperativas cafetaleras de Costa Rica", CIRIEC-España, Revista de Economía Pública, Social y Cooperativa, 55, 253-288.

COMITÉ ESPAÑOL PERMAMENTE DE LA ECONOMIA SOCIAL (1993): Manifiesto-Programa de la Economía Social. En: I Congreso de la Economía Social, Madrid, 11 de diciembre de 1993.

CONGREGADO, E., HERNÁNDEZ, L., MILLÁN, J.M., RAYMOND, J.L., ROIG, J.L., SALAS, V., SÁNCHEZ-ASÍN, J.L. \& SERRANO, L. (2008): El capital humano y los emprendedores en España. Cuaderno no 93: El perfil del emprendedor en España, Septiembre, Ed. Bancaja, Valencia. Disponible en http://obrasocial.bancaja.es. 
DE PABLO, J. \& URIBE, J. (2009): "Emprendimiento de la economía social y desarrollo local: la promoción de incubadoras de economía social en Andalucía", CIRIEC-España, Revista de Economía Pública, Social y Cooperativa, 64, 5-33.

DEFOURNY, J. (1992): "Orígenes, contextos y funciones de un tercer gran sector". En: Defourny, J. y Monzón, J.L. (Dir.): Economía Social. Entre economía capitalista y economía pública, Valencia: Ed. CIRIEC-España, 17-39.

DEMAC, DESARROLLO EMPRESARIAL DE MONTERREY, A.C. (1991): Desarrollo de Emprendedores, Mc Graw Hill, México.

FUENTES, F.J., LARA, F., CONSEJO SOCIAL UCO et al. (2007): Análisis del perfil emprendedor del alumnado universitario y preuniversitario de Córdoba, Servicio de Publicaciones de la Universidad de Córdoba, Consejo Social, Universidad de Córdoba.

FUENTES, F.J. \& SÁNCHEZ, S.M. (2010): Análisis del perfil emprendedor: una perspectiva de género, Estudios de Economía Aplicada, vol. 28-3, 1-28.

GARCÍA SÁNCHEZ, A. \& WANDOSELL, G. (2004): Perfil del emprendedor y proceso de creación de empresas en la Región de Murcia, Murcia: Instituto de Fomento de la Región de Murcia.

GLOBAL ENTREPRENEURSHIP MONITOR (2013): Informe Global Entrepreneurship Monitor (GEM) España 2013, Universidad de Cantabria, Red Española de Equipos Regionales GEM y Centro Internacional Santander Emprendimiento (CISE).

GRAY, D. \& CYR, D. (1994): Cómo evaluar su potencial emprendedor, Ed. Vergara.

HALLORAN, J. (1992): The entrepreneur's guide to starting a successful business, 2nd Edition, Ed. McGraw-Hill, USA, 3-34.

HIAM, A. \& OLANDER, K. (1991): Guía del emprendedor, Ed. Prentice May, México.

KURILOFF, A. \& HEMPHILL, J. (1981): How to start your own business and succeed, 2nd Edition, Ed. McGraw-Hill, USA, 7-15.

KURILOFF, A. \& HEMPHILL, J. (1983): Starting and managing the small business, 2nd Edition, Ed. McGraw-Hill, USA, pp. 16-35.

LAMBING, P. \& KUEHL, C. (1997): Entrepreneurship, Prentice Hall, USA, pp. 9-18.

LONGENECKER J., MOORE, C. \& PETTY, W. (1994): Small Business management, Ed. South-western Publishing Co., 9th Edition, USA, pp. 2-28.

MAESTRO, J.C. (1998): En busca de tu estrella polar, Penta, La Coruña.

MARTíN, S., LEJARRIAGA, G. \& ITURRIOZ, J. (2007): "Consideraciones sobre la naturaleza del capital social en las sociedades cooperativas de trabajo asociado", REVESCO, Revista de Estudios Cooperativos, 91, 93-119. 


\section{LAS SOCIEDADES COOPERATIVAS Y LABORALES COMO ARTÍFICES DEL EMPRENDIMIENTO EMPRESARIAL. ANÁLISIS COMPARATIVO DEL PERFIL DEL EMPRENDEDOR DE AMBAS FIGURAS EN EL CONTEXTO DE ANDALUCÍA}

McCLELLAND, D. (1961): The achieving society, Ed. John Wiley: New York, USA.

MELIÁN, A., CAMPOS, V. \& SANCHIS, J.R. (2011): "Emprendimiento social y empresas de inserción en España. Aplicación del método delphi para la determinación del perfil del emprendedor y las empresas sociales creadas por emprendedores", REVESCO, Revista de Estudios Cooperativos, $106,150-172$.

MINISTERIO DE EMPLEO Y SEGURIDAD SOCIAL (2012): Avance.- Resumen Situación Empresas de Economía Social y sus Trabajadores en Situación de Alta en la Seguridad Social a 31 de Diciembre de 2012, Edita: Dirección General del Trabajo Autónomo, de la Economía Social y de la Responsabilidad Social de las Empresas. Elabora: Subdirección General de la Economía Social y de la Responsabilidad Social de las Empresas.

PARGA, E., MARTÍN, C. \& CRIADO, F. (2013): "La Innovación Organizativa y de Gestión como Motor de Dinamización Empresarial", Journal of Technology Management \& Innovation, 8:2, 132-143.

PÉREZ, F. (Dir.), MÁS, M., MAUDOS, J., QUESADA, J., SERRANO, L., CHORÉN, P., CUCARELLA, V., HERNÁNDEZ, L., ROBLEDO, J.C., SOLAZ, M. \& SOLER, A. (2011): Crecimiento y competitividad. Trayectoria y perspectivas de la economía española, Informe Fundación BBVA-Ivie.

PETERS, T. \& WATERMAN, R.H. (1984): En Busca de la Excelencia. Lecciones de las empresas mejor gestionadas de los Estados Unidos, Ediciones Folio, Barcelona.

RIDDERSTRALE, J. \& KJELL, A.N. (2004): Karaoke Capitalism. Management para la humanidad, Prentice Hall, Madrid.

RONSTADT, R. (1985): Entrepreneurship, Ed. Lord Publishing Co., 1-46.

SEMPERE, F. \& HERVÁS-OLIVER, J.L. (2011): “¿Qué explica la innovación en las PyMEs?”, Dirección y Organización, 43, 5-15.

SHAPERO, A. \& SOKOL, L. (1982): "The social dimensions of entrepreneurship". En: Kent, C.A., Sexton, D.L. \& Vesper, K. (Ed.), Encyclopedia of Entrepreneurship, Ed. Prentice Hall, 72-89.

STACEY, N. (1980): The sociology of the entrepreneur, Ed. McMaster University, Canadá.

STEVENSON, H.H., ROBERTS, M. \& GROUSBECK, H.I. (1985): New Business Ventures and the Entrepreneur, Ed. R.D. Irwin, New York, USA, 738 páginas.

VANDERWERF, P. \& BRUSH, C. (1989): "Toward agreement on the focus of entrepreneurship research: progress without definition", Proceedings of The National Academy of Management, Conference, Washington D.C., USA.

VARGAS, A. (1995): "La Excelencia empresarial cooperativa: un debate abierto". En: Mihai, S. (Coord.), La adaptación de la empresa en un sistema en transición. Bucarest: Expert, 624-634. 
VARGAS, A. (1999): "Claves de la excelencia en la gestión de sociedades cooperativas". En: Sociedades Cooperativas. Régimen Jurídico y Gestión Económica, Ibidem Ediciones, Madrid, 285-303.

WENNEKERS, S. \& THURIK, R. (1999): "Linking Entrepreneurship and Economic Growth”. Small Business Economics, 13:1, August, 27-56.

WESTALL, A. (2007): "How can innovation in social enterprise be understood, encouraged and enabled? A social enterprise think piece for the Office of the Third Sector. Cabinet Office. Office of the Third Sector". Disponible en: http://webarchive.nationalarchives.gov.uk/+/http://www.cabinetoffice.gov.uk/upload/assets/www.cabinetoffice.gov.uk/third_sector/innovation_social_enterprise.pdf. 